\title{
Effects of grazing intensity on soil labile organic carbon fractions in a desert steppe area in Inner Mongolia
}

\author{
Jixin Cao ${ }^{1}$, Xiaoping Wang ${ }^{1,2}$, Xiangyang Sun ${ }^{*}$, Lin Zhang ${ }^{1}$, Yun Tian ${ }^{1}$ \\ From 2010 International Conference on Combating Land Degradation in Agricultural Areas (ICCLD'10) \\ Zi'An City, PR China. 11-15 October 2010
}

\begin{abstract}
Grazing can cause changes in soil carbon (C) level. This study aimed to elucidate the response of soil labile organic carbon (SLOC) under four different grazing intensities: non grazing (NG), 0 sheep ha $^{-1}$; light grazing (LG), 0.91 sheep $\cdot$ ha $^{-1}$; moderate grazing (MG), 1.82 sheep $\mathrm{ha}^{-1}$, and heavy grazing (HG), 2.73 sheep.ha ${ }^{-1}$. Results showed that there was no significant difference in total soil organic carbon (TOC) and soil inorganic carbon (SIC) content from three soil depths $(0-15 \mathrm{~cm}, 15-30 \mathrm{~cm}$, and 30-45 cm) under different grazing intensities. However, the SLOC including particulate organic carbon (POC), light fraction organic carbon (LFOC), and readily oxidizable carbon (ROC) content at a depth of 0-15 cm decreased with the increasing grazing intensity among LG, MG and HG. The SLOC content at depths of $15-30 \mathrm{~cm}$ under the NG and LG were significantly higher than that under the MG and the HG. The TOC and SLOC content decreased with increasing depths of soil horizons, but SIC content increased. The variation trend of the density of different soil carbon fractions and the ratio of individual SLOC fractions to TOC were similar to that of the soil carbon content of corresponding fractions. These results indicated that MG and HG treatments caused C loss at 0-30 cm; and SLOC was more sensitive than TOC in response to different grazing intensities.
\end{abstract}

\section{Introduction}

Grasslands of various types comprise approximately $29.4 \%$ of the global land [1]. Soil contains about $90 \%$ of total grassland systems carbon $(\mathrm{C})$ [2], which store up to $30 \%$ of the world's belowground C [3]. Grazing, as one of the most important approaches, could modify the soil $\mathrm{C}$ stock in the grassland ecosystem and potentially influence climate change [4-7]. The investigation of the herbivores impact on the regulation of soil $C$ is important to understand grassland ecosystems and to evaluate the contribution of grasslands to global C fluxes [8]. However, there are controversial reports on the effect of grazing on soil organic $\mathrm{C}$ level. Some studies reported that grazing increased soil $\mathrm{C}$ levels $[2,9,10]$. Other

\footnotetext{
* Correspondence: sunxy@bjfu.edu.cn

${ }^{1}$ Key Lab. Soil and Water Conservation and Desertification Combating, Ministry of Education, College of Soil and Water Conservation, Beijing Forestry University, Beijing, China

Full list of author information is available at the end of the article
}

studies reported grazing had either no effect on [11] or decreased soil C levels [12-14]. The differences in soil C response to grazing may reflect differences in climate, inherent soil properties, landscape position, plant community composition and grazing management practices among reported studies [2].

Most of those previous studies focus on the effects of medium and long-term grazing on total soil organic carbon (TOC), while there are few for the soil labile organic carbon (SLOC) pool. Although TOC is an established indicator of soil quality, small changes in TOC resulting from changes in soil management are often difficult to measure, especially in a short-duration [15-18]. However, changes in small but relatively labile fractions of TOC may provide an early indication of soil degradation or improvement in response to management practices [16]. SLOC refers to carbon subject to intense impact of plants and microorganisms and characterized by its solubility, fast movement and ease of

\section{SpringerOpen ${ }^{\circ}$}

(C) 2013 Cao et al.; licensee Springer This is an open access article distributed under the terms of the Creative Commons Attribution License (http://creativecommons.org/licenses/by/2.0), which permits unrestricted use, distribution, and reproduction in any medium, provided the original work is properly cited. 
mineralization. Terms used to characterize SLOC in global soil science communities include, particulate organic carbon (POC), light fraction organic carbon (LFOC) readily oxidized carbon (ROC), soil microbial biomass carbon $(\mathrm{SMBC})$ and dissolved organic carbon (DOC), etc $[19,20]$. POC refers to the organic carbon which is combined with soil sand fractions $(53 \sim 2000 \mu \mathrm{m})$ and comprises primarily semi-decomposed plant residues $[19,21]$. This fraction can be described as representing an intermediate pool with regards to decomposition [22]. Light fractions of soil is the fraction with a density less than $2.0 \mathrm{~g} \mathrm{~cm}^{-2}$, the carbon of which reflects a mixture of compounds that includes microbial biomass, partially degraded plant material and older, more humified, by-products of decomposition[23,24]. ROC which is easily oxidized by potassium permanganate is considered to be a liable soil carbon pools $[15,16,22,25]$.

Inner Mongolia grassland located in the hinterland of Eurasia is the main body of temperate grasslands in northern China, accounting for about $22 \%$ of the total 400 million ha of grassland of China [26,27]. 39\% of Inner Mongolia grassland is desert steppe [13]. The object of our study is to investigate the effects of different grazing intensities on the soil carbon, especially on soil labile carbon in a desert steppe area in Inner Mongolia of China.

\section{Materials and methods}

\section{Study site}

The study site is located in Shi Dorbod Qi (County), Ulanqab City of Inner Mongolia autonomous region, China (latitude: $41^{\circ} 47^{\prime} \mathrm{N}$, longitude: $111^{\circ} 53^{\prime} \mathrm{E}$, elevation: $1450 \mathrm{~m}$ ). It is characterized by a typically continental climate. According to long-term meteorological observation, the mean annual temperature is $3.4{ }^{\circ} \mathrm{C}$. The three highest monthly mean temperature is $21.5,24.0,23.5^{\circ} \mathrm{C}$ in June, July and August, respectively. The annual precipitation averages $280 \mathrm{~mm}$, with about more than $80 \%$ received from May until September. Annual average total sunshine time is $3118 \mathrm{~h}$, and the annual mean amount of evaporation is $2300 \mathrm{~mm}$. The dominant plant species of the study site were Stipa breviflora, Artemisia frigida and Cleistogenes songorica, accompanied by Convolvulus ammannii, Heteropappus altaicu, Neopallasia pectinata, Kochia prostrate, Caragana stenophylla and Leymus chinensis. The soil of the study site was classified as light chestnut soil [28].

\section{Treatment}

This steppe desert was where the grazing continued from 1988, when herdsmen began to settle down there to live, and due to the lack of effective management measurements, the steppe desert had begun to degradation before the enclosing. In June, 2004, about 50 ha relatively flat, uniform and native dessert steppe was enclosed for grazing. The fence grazing area was divided into three replicated groups by a complete randomized design (Figure 1). According to previous study results $[29,30]$, four 4.4 ha plots which mean four different grazing intensities (NG-non grazing 0, LG-light grazing 0.91, MG-moderate grazing 1.82, HG-heavy grazing 2.73 sheep $\cdot \mathrm{ha}^{-1}$ ) were set up in each group. The local adult Mongolian sheep were the test ones. The period of grazing test was 6 months (June-November) every year from 2004 to 2007. Every morning test sheep were herded to the different sample plots, and every evening they were driven to the sheepfold during the grazing period.

\section{Soil sampling, laboratory and statistics analysis}

Soil sampling was completed in the September of 2007. Twelve sites were randomly sampled in each plot with a soil auger. At each sampling site, soil samples were excavated at depths of 0-15, 15-30 and 30-45 cm. And then, soil samples of the same depth in each plot were mixed into a bulk sample [31]. For each soil sample, an accompanying soil bulk density sample was also taken at a near-by position by using a $100 \mathrm{~cm}^{3}$ soil ring.

Soil samples were air dried and passed through a $2 \mathrm{~mm}$ sieve. TOC content was determined by $\mathrm{H}_{2} \mathrm{SO}_{4}-\mathrm{K}_{2} \mathrm{Cr}_{2} \mathrm{O}_{7}$ pyrogenation method [32]. Soil inorganic carbon was determined by method described by following method [4,32]: $5 \mathrm{~g}$ of $<2 \mathrm{~mm}$ (sieved), air dry soil sample was added to $25 \mathrm{~mL}$ of $3 \mathrm{~mol} \cdot \mathrm{L}^{-1}$ and then determined the volume of the released $\mathrm{CO}_{2}$ after being shaked for $4 \mathrm{~min}$.

Particulate organic matter (POM) was separated from $2 \mathrm{~mm}$ soil following the method described by Burt [22]. $10 \mathrm{~g}$ of $<2 \mathrm{~mm}$ (sieved), air dry soil sample was weighed into a $125 \mathrm{~mL}$ Erlenmeyer flask, and then add

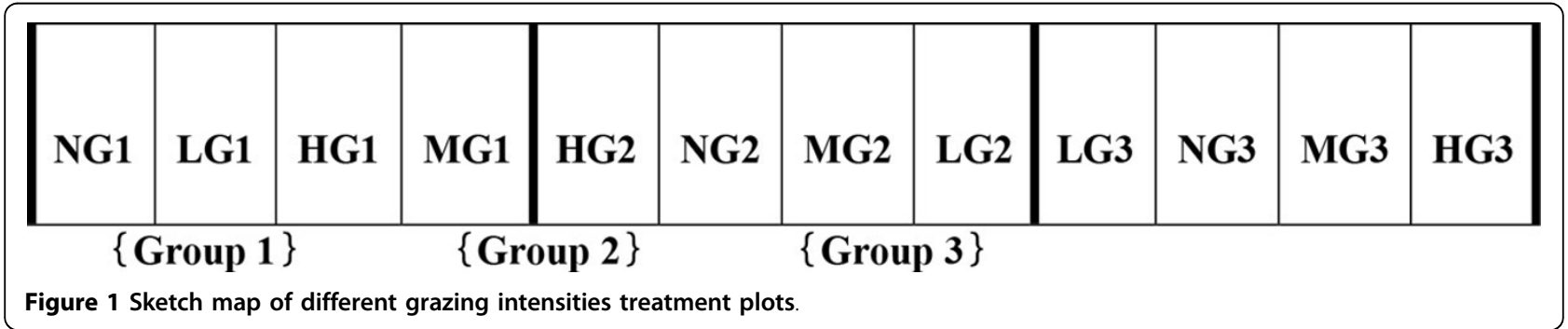


$30 \mathrm{~mL}$ reverse osmosis deionized (RODI) water. Stopper sample and shake for $15 \mathrm{~h}$ at 200 oscillations. $\mathrm{min}^{-1}$. After that, soil suspension was rinsed by RODI water to sieve through $53 \mu \mathrm{m}$ mesh. The remains on the sieve were oven-dried at $110^{\circ} \mathrm{C}$ and weighed. The carbon content of POM was determined by the method of TOC analysis.

Light fraction (LF) organic carbon (LFOC) determination followed Gregorich and Ellert [23]: $25 \mathrm{~g}$ air-dry soil $(<2 \mathrm{~mm})$ was weighed into a $250 \mathrm{~mL}$ centrifuge tube and added with $50 \mathrm{~mL} \mathrm{NaI}$ solution $\left(1.7 \mathrm{~g} \cdot \mathrm{cm}^{-3}\right)$. The mixture was shaken for $1 \mathrm{~h}$ at $200 \mathrm{rpm}$ and then centrifuged for $20 \mathrm{~min}$ at $1000 \mathrm{rpm}$. Then the surface of $\mathrm{NaI}$ solution was filtered through a $0.45-\mu \mathrm{m}$ nylon filter with aspirating. The LF which remained on the filter was washed with $75 \mathrm{~mL} \mathrm{CaCl} 2$ solution followed by $75 \mathrm{~mL}$ distilled water to separate NaI from LF. Then LF was washed from filter to preweighed drying tins. After that, the tins were placed in the oven at $60^{\circ} \mathrm{C}$ to obtain the dry weight. Organic carbon in LF was also determined by $\mathrm{H}_{2} \mathrm{SO}_{4}-\mathrm{K}_{2} \mathrm{Cr}_{2} \mathrm{O}_{7}$ oxidation method.

ROC was determined by using $0.02 \mathrm{~mol} \cdot \mathrm{L}^{-1} \mathrm{KMnO}_{4}$ oxidation method described by Weil et al. [16] and Burt [22]. Earlier studies $[25,33]$ suggested that $0.333 \mathrm{~mol} \mathrm{l. \textrm {L } ^ { - 1 }}$ $\mathrm{KMnO}_{4}$ was a comfortable oxidizing agent. However, Weil, et al. [16] found that highly concentrated solutions $\left(0.333 \mathrm{~mol} \mathrm{l.} \mathrm{L}^{-1}\right)$ of $\mathrm{KMnO}_{4}$ were difficult to work with and tend to react with a large fraction of soil $\mathrm{C}$ which was not well distinguished from TOC and then improved the former method into a highly simplified method with $0.02 \mathrm{~mol} \cdot \mathrm{L}^{-1} \mathrm{KMnO}_{4}$. Concrete procedures are as follows: stocking solutions of $0.02 \mathrm{~mol} \cdot \mathrm{L}^{-1} \mathrm{KMnO}_{4}$ in $0.1 \mathrm{~mol} \cdot \mathrm{L}^{-1}$ $\mathrm{CaCl}_{2}$ and standard $\mathrm{KMnO}_{4}$ working solutions from 0 to $0.02 \mathrm{~mol} \cdot \mathrm{L}^{-1}$ were prepared. $5 \mathrm{~g}$ of $<2 \mathrm{~mm}$ (sieved), air dry soil sample was weighed into centrifuge tube. The soil samples were reacted with $20 \mathrm{~mL}$ the $\mathrm{KMnO}_{4}$ in 0.1 $\mathrm{mol} \cdot \mathrm{L}^{-1} \mathrm{CaCl}_{2}$ solution. The centrifuge tube was shaken for $2 \mathrm{~min}$ and then allowed to settle for $10 \mathrm{~min} .0 .5 \mathrm{~mL}$ supernatant solution was diluted to $50 \mathrm{~mL}$ and absorbance was measured on a spectrophotometer which was set to read at $550 \mathrm{~nm}$. The content of ROC was determined by the consumed $\mathrm{KMnO}_{4}$.

Soil carbon density refers to the carbon stock at specified depth in a unit area, and was calculated by multiplying carbon content of unit volume and the thickness of the given soil horizons [34,35].

The data were analyzed by SPSS 17.0 with a one-way analysis of variance (ANOVA). The least significant difference (LSD) was performed to test differences when $F$ values from ANOVA were significant $(\mathrm{p}<0.05)$.

\section{Results and discussions}

Figure 2 TOC contents in different grazing intensity. Statistics in Figure 2 are mean values with standard

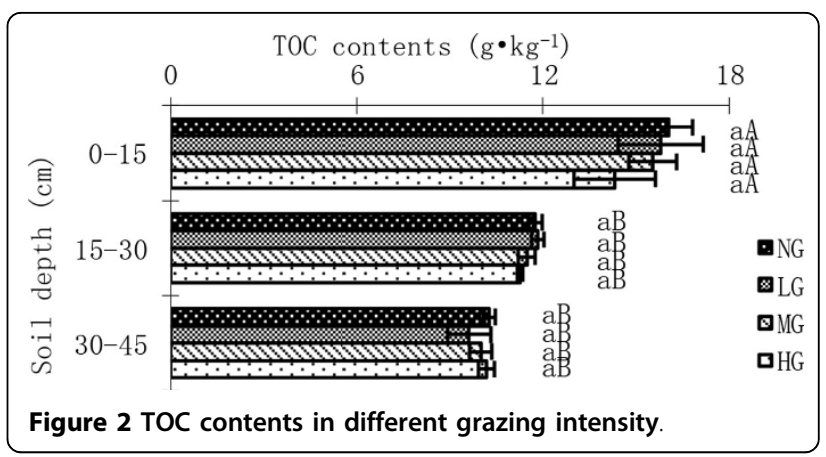

errors. Different small case letters indicate a significant difference with different grazing treatments $(\mathrm{p}<0.05)$, and different upper case letters indicate a significant difference with different soil depth $(\mathrm{p}<0.05)$. The same explanation also applies to Figures 3, 4, 5, and 6.

The content of TOC decreased with increasing grazing intensity at soil horizon of $0-15 \mathrm{~cm}$ (Figure 2). However, There was no significant difference of TOC content between different grazing treatments at all three depths $(\mathrm{p}>0.05)$. TOC contents were the highest at the surface horizon $(0-15 \mathrm{~cm})$ and decreased with increasing soil depth. For all grazing treatments, TOC contents at the surface horizon were significantly higher than those at $15-30 \mathrm{~cm}(\mathrm{p}<0.05)$, which were higher than those at $30-45 \mathrm{~cm}$ with no significant differences $(\mathrm{p}>0.05)$ (Figure 2).

SIC contents were not significantly different with increasing grazing intensity at all three depth $(0-15 \mathrm{~cm}$, $15-30 \mathrm{~cm}$ and $30-45 \mathrm{~cm})(\mathrm{p}>0.05)$ (Figure.3). The variation trend of SIC contents with increasing soil depth was opposite to that of TOC. SIC contents of four grazing treatments were significant lower at the surface horizon than those at $15-30 \mathrm{~cm}$, which in turn were also significant lower than those at horizon of $30-45 \mathrm{~cm}$ ( $\mathrm{p}>$ 0.05) (Figure 3).

The soil organic carbon is determined by $\mathrm{C}$ input mainly from aboveground litter production, root turnover and animal excreta, and $C$ output through soil

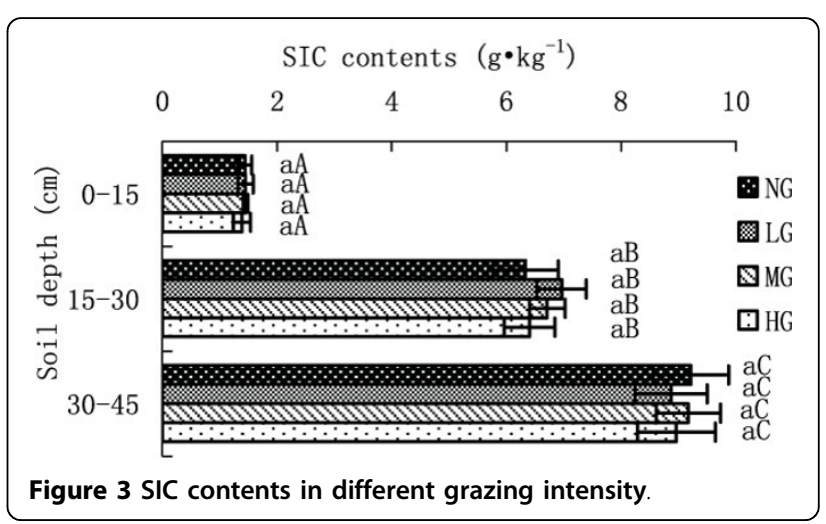




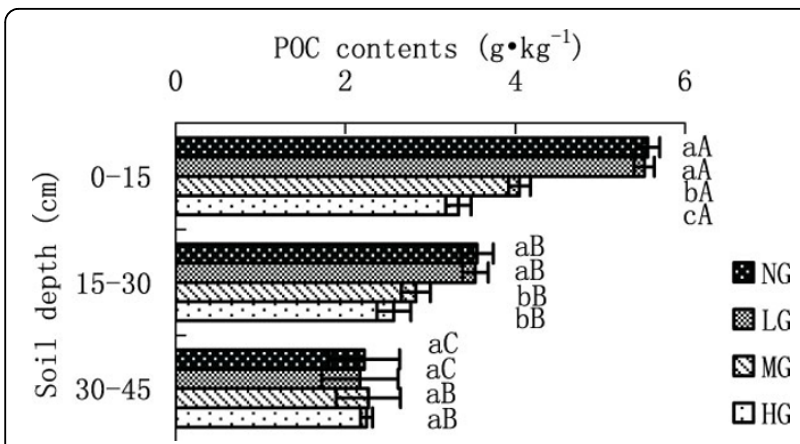

Figure 4 POC contents in different grazing intensity.

respiration, erosion and leaching s4]. In our study, increasing grazing intensity did not cause significant variation for TOC contents at all three soil horizon. This may be explained by that TOC pool size and distribution reflects past carbon inputs and long-term accumulation process, and tends to respond slowly to management practices changes $[15,36,37]$. This result is consistent with the study result of Wang [11], but inconsistent with some other studies $[2,9,10,12-14]$. This is mainly due to the differences of environment conditions and grazing time. Nevertheless, TOC was sensitive to overgrazing and slow to recover merely by enclosure when it declined following overgrazing in the semiarid typical steppes in Inner Mongolia [4].

Soil inorganic carbon is composed of lithogenic inorganic carbon and secondary carbonate [38], and most of SIC is in the form of calcium carbonate [39]. According to Pan's estimation [39], soil carbon stock of China was $110 \mathrm{Pg}\left(1 \mathrm{Pg}=10^{15} \mathrm{~g}\right)$, including $50 \mathrm{Pg}$ TOC and $60 \mathrm{Pg}$ SIC, which was mainly stored in Northwest and North China. Our study results show that after short-term grazing, SIC differed insignificantly with increasing grazing intensity at all three soil horizons. This result is consistent with Stavi's study [40]. However, Reeder et al. [41] found that SIC content increased after long-term heavy grazing compared with non-grazed treatment in short-grass steppes.

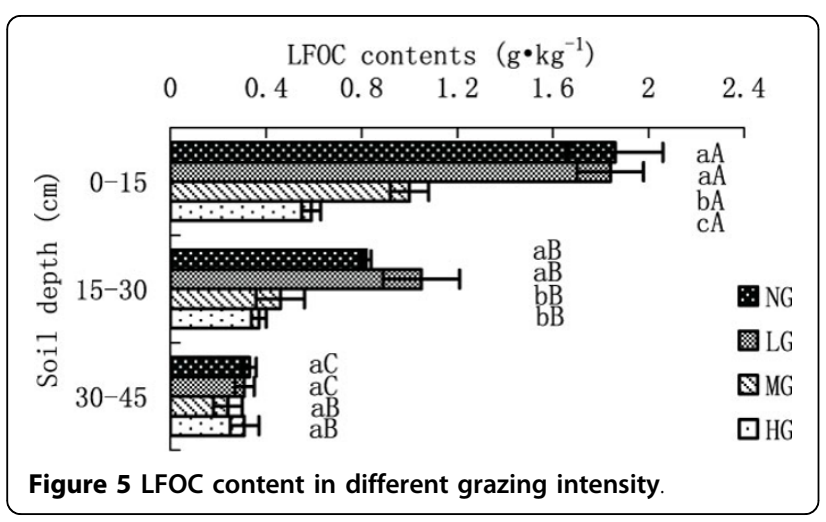

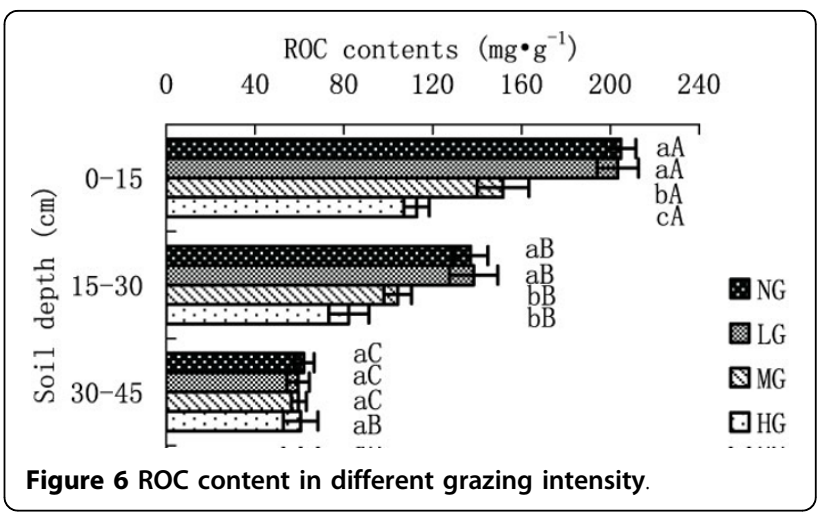

For all the grazing treatments, TOC contents decreased with increasing soil depths, while SIC contents increased. These results are consistent with Yang [42].

\section{SLOC content in different grazing intensities $P O C$ content in different grazing intensities}

POC contents tended to decrease with increasing grazing intensity at 0-15 cm (NG-5.56, LG-5.52, MG-4.05 and HG-3.33 g. $\mathrm{kg}^{-1}$ ) and 15-30 cm (NG-3.55, LG-3.53, MG-2.83 and HG-2.57 g. $\mathrm{kg}^{-1}$ ) soil horizon among LG, MG and HG (Figure 4). POC content in HG at 0-15 cm was significantly lower than that in MG, which in turn was significantly lower than that in LG and NG(p < $0.05)$. The content in LG was similar to that in NG at $0-15 \mathrm{~cm}$. The POC content in HG at $15-30 \mathrm{~cm}$ was similar to that in MG, but significantly lower than other two gazing treatments $(\mathrm{p}<0.05)$. Grazing did not cause significant differences at $30-45 \mathrm{~cm}$ with increasing intensity. The POC contents in NG and LG were significantly decreased with increasing soil depth of $0-45 \mathrm{~cm}(\mathrm{p}<$ 0.05). The POC contents in MG and HG at surface horizon were significantly higher than that at $15-30 \mathrm{~cm}(\mathrm{p}$ $<0.05$ ), which were similar to those at $30-45 \mathrm{~cm}$.

\section{LFOC content in different grazing intensity}

Grazing caused LFOC content in a significant decrease at surface horizon (NG-1.86, LG-1.84, MG-1.00 and HG-0.59 g.kg $\left.{ }^{-1}\right)$ among LG, MG and HG ( $\left.<0.05\right)$, the LFOC content of which was the lowest $\left(0.59 \mathrm{~g} \cdot \mathrm{kg}^{-1}\right)$ (Figure 5). The LFOC content in LG at $0-15 \mathrm{~cm}$ was similar to that in NG, which was also significantly higher than that in MG and HG. The LFOC contents in NG and LG at 15-30 cm (NG-0.82, LG-1.05, MG-0.46 and HG-0.37 g. $\mathrm{kg}^{-1}$ ) were significantly higher than those in MG and HG ( $\mathrm{p}<0.05)$. There were not significant differences at $30-45 \mathrm{~cm}$ between different gazing treatments. The LFOC contents in NG and LG were significantly decreased with increasing soil depth of $0-45 \mathrm{~cm}$ ( $\mathrm{p}<0.05)$. The LFOC contents in MG and HG at surface horizon were significantly higher than that at $15-30$ $\mathrm{cm}(\mathrm{p}<0.05)$, which were similar to that at $30-45 \mathrm{~cm}$. 


\section{$R O C$ content in different grazing intensities}

ROC differed significantly at surface horizon (NG204.72, LG-204.38, MG-151.65 and HG-112.74 mg. $\mathrm{kg}^{-1}$ ) among LG, MG and HG ( $\mathrm{p}<0.05)$, in which the ROC content was the lowest (Figure 6). The ROC content in LG was slightly lower than that in NG at surface horizon, but with no significant differences. At $15-30 \mathrm{~cm}$, ROC contents (NG-137.00, LG-138.38, MG-104.46 and HG-82.22 $\left.\mathrm{mg} \cdot \mathrm{kg}^{-1}\right)$ in NG and LG were significantly higher than those in MG and HG ( $\mathrm{p}<0.05)$. There were no significant differences among different grazing intensities at 30-45 cm horizon. ROC contents in NG, LG and MG decreased significantly with increasing soil depth. ROC content of HG treatment at surface horizon was significantly higher than that at $15-30 \mathrm{~cm}$, which was slightly higher than that at $30-45 \mathrm{~cm}$, but with no significant differences.

While TOC did not change obviously, its labile component may decrease substantially under grazing [4]. After 22 years' grazing in Leymus chinensis steppe, ROC content ( $0.333 \mathrm{~mol} \cdot \mathrm{L}^{-1} \mathrm{KMnO}_{4}$ oxidization) and SMBC content at $0-10 \mathrm{~cm}$ decreased by $22.0 \%$ and $27.9 \%$ respectively, while TOC content decreased insignificantly [18]. The imposition of a cattle grazing pressure is higher than the average for 6 and 8 year periods caused in a significant reduction in SMBC which decreased by $24 \%$ and $51 \%$, while the TOC contents were similar [43]. We found similar trend in our study: at a soil depth of $0-15 \mathrm{~cm}$, compared with LG treatment, POC, LFOC, and ROC contents of MG and HG treatments decreased by $27 \%$ and $40 \%, 46 \%$ and $68 \%, 25 \%$ and $45 \%$, respectively. Therefore, these SLOC properties measured by different methods responded more rapidly to land management practices, and can provide a more sensitive measure of changes in the organic matter status of soils Than TOC $[15,16,23,43,44]$.

In our results, we also found that TOC and SLOC contents at surface horizon were significantly higher than those at sub horizon $(15-30 \mathrm{~cm})$. This is due to that TOC is mainly from soil surface $\mathrm{C}$ accumulation including litter, roots, excrement and urine of animals in rangeland. Additionally, SLOC contents decreased more rapidly with increasing depth compared with TOC, especially in NG and LG treatments. This might be explained by that the different distribution pattern of various components of soil organic carbon in the soil profiles [45].

Statistics in Table 1 are mean values with standard errors in brackets. Different small case letters in a row mean significant different with different grazing treatment $(\mathrm{p}<0.05)$, and different upper case letters in a row mean significant different with soil depth $(\mathrm{p}<0.05)$. The same explanation applies to Table 2.
Table 1 Comparison of soil organic carbon density in different grazing intensity

\begin{tabular}{|c|c|c|c|c|c|}
\hline \multirow[t]{2}{*}{ Property } & \multirow{2}{*}{$\begin{array}{c}\text { Depth } \\
(\mathrm{cm})\end{array}$} & \multicolumn{4}{|c|}{ Treatment } \\
\hline & & NG & LG & MG & HG \\
\hline \multirow[t]{3}{*}{$\begin{array}{l}\text { TOC } \\
\mathrm{kg}^{\mathrm{m}}{ }^{-2}\end{array}$} & $0-15$ & $\begin{array}{c}3.22(0.18) \\
a A\end{array}$ & $\begin{array}{c}3.12(0.27) \\
a A\end{array}$ & $\begin{array}{c}3.17(0.20) \\
a A\end{array}$ & $\begin{array}{c}2.91(0.28 \\
a A\end{array}$ \\
\hline & $15-30$ & $\begin{array}{c}2.48(0.06) \\
a B\end{array}$ & $\begin{array}{c}2.41(0.05) \\
a B\end{array}$ & $2.38(0.06) \mathrm{aB}$ & $\begin{array}{c}2.31(0.03 \\
a B\end{array}$ \\
\hline & $30-45$ & $\begin{array}{c}2.18(0.01) \\
a B\end{array}$ & $\begin{array}{c}2.05(0.16) \\
a B\end{array}$ & $\begin{array}{c}2.12(0.11) \\
a B\end{array}$ & $\begin{array}{c}2.18(0.09 \\
a B\end{array}$ \\
\hline \multirow[t]{3}{*}{$\begin{array}{c}\mathrm{SIC} \\
\mathrm{kg} \cdot{ }^{m-2}\end{array}$} & $0-15$ & $\begin{array}{c}0.29(0.02) \\
a A\end{array}$ & $\begin{array}{c}0.29(0.03) \\
a A\end{array}$ & $\begin{array}{c}0.30(0.01) \\
\mathrm{aA}\end{array}$ & $\begin{array}{c}0.28(0.03 \\
a A\end{array}$ \\
\hline & $15-30$ & $\begin{array}{c}1.33(0.12) \\
a B\end{array}$ & $\begin{array}{c}1.42(0.08) \\
a B\end{array}$ & $\begin{array}{c}1.39(0.09) \\
a B\end{array}$ & $\begin{array}{c}1.31(0.09 \\
a B\end{array}$ \\
\hline & $30-45$ & $\begin{array}{c}1.96(0.13) \\
\mathrm{aC}\end{array}$ & $\begin{array}{c}1.89(0.12) \\
\mathrm{aC}\end{array}$ & $\begin{array}{c}1.79(0.24) \mathrm{a} \\
\mathrm{C}\end{array}$ & $\begin{array}{c}1.92(0.17) \\
\mathrm{aC}\end{array}$ \\
\hline \multirow[t]{3}{*}{$\begin{array}{l}\mathrm{POC} \\
\mathrm{kg} \cdot{ }^{\mathrm{m}-2}\end{array}$} & $0-15$ & $\begin{array}{c}\text { 1.12(0.02) } \\
\mathrm{aA}\end{array}$ & $\begin{array}{c}1.09(0.01) \\
a A\end{array}$ & $0.83(0.03) \mathrm{bA}$ & $\begin{array}{c}0.68(0.04 \\
\text { CA }\end{array}$ \\
\hline & $15-30$ & $\begin{array}{c}0.75(0.03) \\
a B\end{array}$ & $\begin{array}{c}0.72(0.03) \\
a B\end{array}$ & $\begin{array}{c}0.58(0.02) \\
b B\end{array}$ & $\begin{array}{c}0.53(0.04 \\
b B\end{array}$ \\
\hline & $30-45$ & $\begin{array}{c}0.47(0.09) \\
\mathrm{aC}\end{array}$ & $\begin{array}{c}0.46(0.09) \\
\mathrm{aC}\end{array}$ & $\begin{array}{c}0.48(0.09) \\
a B\end{array}$ & $\begin{array}{c}0.48(0.02 \\
a B\end{array}$ \\
\hline \multirow[t]{3}{*}{$\begin{array}{l}\text { LFOC } \\
\mathrm{g}^{\cdot m-2}\end{array}$} & $0-15$ & $\begin{array}{c}373.26 \\
(29.94) \mathrm{aA}\end{array}$ & $\begin{array}{c}363.29 \\
(30.84) \mathrm{aA}\end{array}$ & $\begin{array}{c}203.61 \\
(14.34) \mathrm{bA}\end{array}$ & $\begin{array}{c}120.78 \\
(11.53) \mathrm{CA}\end{array}$ \\
\hline & $15-30$ & $\begin{array}{c}173.27 \\
(4.92) \mathrm{aB}\end{array}$ & $\begin{array}{c}214.01 \\
(32.34) \mathrm{aB}\end{array}$ & $\begin{array}{c}95.85 \\
(21.06) \mathrm{bB}\end{array}$ & $\begin{array}{c}75.99 \\
(7.37) \mathrm{bB}\end{array}$ \\
\hline & $30-45$ & $\begin{array}{c}69.67 \\
(7.63) \mathrm{aC} \\
\end{array}$ & $\begin{array}{c}65.95 \\
(8.50) \mathrm{aC} \\
\end{array}$ & $\begin{array}{c}51.52 \\
(13.66) \mathrm{aB} \\
\end{array}$ & $\begin{array}{c}65.58 \\
(13.21) \mathrm{aB} \\
\end{array}$ \\
\hline \multirow[t]{3}{*}{$\begin{array}{l}\mathrm{ROC} \\
\mathrm{g}^{\cdot m-2}\end{array}$} & $0-15$ & $\begin{array}{c}41.04 \\
(1.25) \mathrm{aA}\end{array}$ & $\begin{array}{c}40.11 \\
(1.43) \mathrm{aA}\end{array}$ & $\begin{array}{c}30.99 \\
(2.71) \mathrm{bA}\end{array}$ & $\begin{array}{c}22.94 \\
(1.72) \mathrm{cA}\end{array}$ \\
\hline & $15-30$ & $\begin{array}{c}28.89 \\
(2.14) a B\end{array}$ & $\begin{array}{c}28.21 \\
(2.12) \mathrm{aB}\end{array}$ & $\begin{array}{c}21.63 \\
(1.41) \mathrm{bB}\end{array}$ & $\begin{array}{c}16.82 \\
(1.68) \mathrm{bB}\end{array}$ \\
\hline & $30-45$ & $\begin{array}{c}13.25 \\
(1.20) \mathrm{aC}\end{array}$ & $\begin{array}{c}12.67 \\
(1.22) \mathrm{aC}\end{array}$ & $\begin{array}{c}12.59 \\
(0.68) \mathrm{aC}\end{array}$ & $\begin{array}{c}12.99 \\
(1.85) \mathrm{aB}\end{array}$ \\
\hline
\end{tabular}

\section{Soil organic carbon density}

Table 1 shows that densities of POC, LFOC, and ROC decreased significantly with increasing grazing intensity among LG, MG and HG at surface horizon. Densities of three SLOC fractions in LG were similar to those in NG at surface horizon. At $0-30 \mathrm{~cm}$ soil depth, densities of POC, LFOC, and ROC in MG and HG accounted for $78 \%$ and $67 \%, 52 \%$ and $34 \%, 77 \%$ and $58 \%$ of corresponding density in LG, respectively. Densities of SLOC at $15-30 \mathrm{~cm}$ in NG and LG were significantly higher than those in MG and HG $(\mathrm{p}<0.05)$. There were no significant differences for SLOC at 30-45 cm between different grazing treatments. Effects of grazing on densities of TOC and SIC were not significant at all three soil depths. The densities of TOC, POC, LFOC, and ROC decreased with increasing soil depth in all grazing treatments. However, SIC densities increased with increasing soil depth. These variation trends of different $\mathrm{C}$ fractions densities were similar to those of $\mathrm{C}$ contents of corresponding fractions. 
Table 2 Rate of soil labile carbon to total organic carbon content in different grazing intensity (\%)

\begin{tabular}{cccccc}
\hline Property & $\begin{array}{c}\text { Depth } \\
(\mathbf{c m})\end{array}$ & \multicolumn{4}{c}{ Treatment } \\
\cline { 3 - 6 } & & NG & LG & MG & HG \\
\hline POC/ & $0-15$ & 34.91 & 35.52 & 26.11 & 23.79 \\
TOC & & $(3.04) \mathrm{aA}$ & $(1.69) \mathrm{aA}$ & $(0.59) \mathrm{bA}$ & $(3.15) \mathrm{bA}$ \\
\cline { 2 - 6 } & $15-30$ & 30.22 & 29.83 & 24.62 & 22.80 \\
& & $(1.55) \mathrm{aAB}$ & $(0.90) \mathrm{aAB}$ & $(1.26) \mathrm{bA}$ & $(1.95) \mathrm{bA}$ \\
\cline { 2 - 6 } & $30-45$ & 21.65 & 22.71 & 22.48 & 22.12 \\
& & $(4.21) \mathrm{aB}$ & $(4.74) \mathrm{aB}$ & $(3.09) \mathrm{aA}$ & $(0.59) \mathrm{aA}$ \\
\hline LFOC/ & $0-15$ & 11.75 & 11.93 & 6.45 & 4.24 \\
TOC & & $(1.55) \mathrm{aA}$ & $(1.80) \mathrm{aA}$ & $(0.46 \mathrm{bA}$ & $(0.59) \mathrm{bA}$ \\
\cline { 2 - 6 } & $15-30$ & 7.00 & 8.93 & 4.00 & 3.28 \\
& & $(0.08) \mathrm{aB}$ & $(1.50) \mathrm{aA}$ & $(0.81) \mathrm{bB}$ & $(0.28) \mathrm{bA}$ \\
\cline { 2 - 6 } & $30-45$ & 3.19 & 3.23 & 2.45 & 3.03 \\
& & $(0.37) \mathrm{aC}$ & $(0.41) \mathrm{aB}$ & $(0.67) \mathrm{aB}$ & $(0.64) \mathrm{aA}$ \\
\hline ROC/ & $0-15$ & 1.29 & 1.31 & 0.98 & 0.80 \\
TOC & & $(0.09) \mathrm{aA}$ & $(0.16) \mathrm{aA}$ & $(0.11) \mathrm{bA}$ & $(0.09) \mathrm{CA}$ \\
\cline { 2 - 6 } & $15-30$ & 1.17 & 1.17 & 0.91 & 0.73 \\
& & $(0.07) \mathrm{aA}$ & $(0.10) \mathrm{aA}$ & $(0.04) \mathrm{bA}$ & $(0.09) \mathrm{bA}$ \\
\cline { 2 - 6 } & 0.61 & 0.62 & 0.60 & 0.59 \\
& $30-45$ & $(0.06) \mathrm{aB}$ & $(0.01) \mathrm{aB}$ & $(0.05) \mathrm{aB}$ & $(0.06) \mathrm{aA}$ \\
\hline & & & &
\end{tabular}

Soil $\mathrm{C}$ density is decided by the contents of different soil $\mathrm{C}$ fractions, soil bulk density and contents of gravel. In our study site, there are little gravels in 0-45 cm depth soil. Therefore, soil $\mathrm{C}$ contents and bulk density are the main factor for calculating correspondingly soil $\mathrm{C}$ density. Our results showed that the variation trends of individual $\mathrm{C}$ fractions density were similar to those of correspondingly $\mathrm{C}$ contents with increasing grazing intensity. This is due to that soil bulk densities were insignificant differences with increasing grazing intensity at each soil horizons (data not shown). Some studies showed that the effects of herbivores trampling were significant, which caused increasing soil bulk density, especially in surface horizon [46-49]. However, other studies showed that grazing had no significant effects on soil bulk density $[40,43,50]$. The differences of these results may be due to the different inherent soil properties and grazing time.

\section{Ratio of Labile carbon}

Table 2 shows that ratios of POC content to TOC content which varied from 34.91 to $23.79 \%$ at surface horizon in NG and LG treatments were significantly higher than those in MG and HG ( $\mathrm{p}<0.05)$. This trend of ratio was similar to that of ratio of LFOC content to TOC content which varied from 11.75 to $4.24 \%$ at surface horizon. Ratio of ROC content to TOC content varied from 1.29 to $0.80 \%$ at the surface horizon. For ratio of ROC content to TOC content, grazing caused significantly decreased at surface horizon with increasing intensity among LG, MG and HG. However, ratio of ROC content to TOC content in LG is similar to that in NG at surface horizon. At $15-30 \mathrm{~cm}$, ratios of POC content to SOC content in NG and LG were significant higher than those in MG and HG ( $\mathrm{p}<0.05)$. This trend is similar to those for ratios of LFOC content to TOC content and ROC content to TOC content at $15-30 \mathrm{~cm}$. At $30-45 \mathrm{~cm}$, there were no significant differences between different grazing treatments for all ratio properties. All these ratio properties decreased with increasing soil depth.

The ratio of SLOC contents to TOC contents might be correlated with the difference in the distribution of plant root systems, the concentration of soil organic carbon, and the content of soil clay as well $\left[{ }^{19]}\right.$. The relative changes in SLOC contents and TOC contents are more readily seen when they are expressed as a ratio of SLOC to TOC, which is lower for the heavy grazing [43]. Our results were consistent with this conclusion. Table 2 showed that the ratios of SLOC to TOC were all decreased with increasing grazing intensity among LG, MG and HG at $0-30 \mathrm{~cm}$. The ratios had no significant changes at 30-45 cm, because of no significant differences of three SLOC fractions and TOC.

\section{Conclusions}

There was no significant difference in TOC and SIC content from three soil depths $(0-15 \mathrm{~cm}, 15-30 \mathrm{~cm}$, and 30-45 cm) under different grazing intensities. However, the three SLOC fractions (POC, LFOC and ROC) content at a depth of 0-15 cm decreased with increasing grazing intensity among LG, MG and HG. SLOC fractions content of LG were similar to those of NG at 0-15 $\mathrm{cm}$. Three SLOC fractions content under the NG and LG were significantly higher than under the MG and the HG at $15-30 \mathrm{~cm}$, however, grazing caused no significant differences at $0-45 \mathrm{~cm}$. The TOC and SLOC content decreased with increasing depths of soil horizons, but SIC content increased.

The variation trend of the density of different soil C fractions and the ratio of individual SLOC fractions to TOC were similar to those of the soil carbon content of corresponding fractions. Compared with NG and LG, HG and MG treatments caused the density of different SLOC fractions and the ratios of individual SLOC fractions to TOC significantly decreased at $0-30 \mathrm{~cm}$. The density of different SLOC fractions and ratios of individual SLOC fractions to TOC decreased with increasing soil depths of soil horizons, however, SIC density increased.

Therefore, MG and HG treatments caused loss of soil organic carbon, and SLOC was more sensitive than TOC in response to different grazing intensities. 


\section{Competing interests}

The authors declare that they have no competing interests.

\section{Acknowledgements}

The study was supported by a Chinese National Natural Science Foundation (30671660), New Century Excellent Talents in University of China ministry of education (NCET-05-0137), Specialized Research Fund for the Doctoral Program of Higher Education of China ministry of education (20050022014), Research and Demonstration of Carbon Sequestration Technology in the Northern Fastgrowing Forest and Orchard Systems (2008BAD95B07), and Construction Project of Carbon Sequestration Capacity Accounting and Monitoring System in Beijing Urban Green Space System. The authors acknowledge the assistance of Fengling Shi, Guodong Han, Hudong Hao, Zhongwu Wang (Inner Mongolia Agricultural University) and Alata, Bao yin (Research Station of Inner Mongolia Academy of Agriculture and Animal Husbandry) with access to study sites and sampling. Finally, we appreciate the insightful suggestions of Dr. Tianshan Zha (Beijing Forestry University) and Dr. Xiaohui Yang (Chinese Academy of Forestry) during the preparation of the manuscript.

\section{Declarations}

The publication costs for this article were funded by Scientific \& Technical Development Inc

This article has been published as part of SpringerPlus Volume 2 Supplement 1, 2013: Proceedings of the 2010 International Conference on Combating Land Degradation in Agricultural Areas (ICCLD'10). The full contents of the supplement are available online at http://www.springerplus.com/ supplements/2/S1.

\section{Authors' details}

${ }^{1}$ Key Lab. Soil and Water Conservation and Desertification Combating, Ministry of Education, College of Soil and Water Conservation, Beijing Forestry University, Beijing, China. ${ }^{2}$ Beijing Forestry Carbon Administration (Beijing Forestry and Parks Department of International Cooperation), Beijing, China.

Published: 11 December 2013

\section{References}

1. Watson RT, Noble IR, Bolin B, Ravindranath NH, Verardo DJ, Dokken DJ: Intergovermental panel on climate change special report: land use, land-use change and forestry. Cambridge University Press, Cambridge, UK; 2000, 4.

2. Reeder JD, Schuman GE: Influence of livestoNG grazing on C sequestration in semi-arid mixed-grass and short rangelands Environment Pollution 2002, 116(3):457-463.

3. Risch AC, Jurgensen DA, Frank DA: Effects of grazing and soil microclimate on decomposition rates in a spatio-temporally heterogeneous grassland. Plant and Soil 2007, 298(1-2):191-201.

4. Cui XY, Wang YF, Niu HS, Wu SP, Ewald S, Rogasilk J, Fleckenstein J, Tang Y: Effect of long-term grazing on soil organic carbon content in semiarid steppes in Inner Mongolia. Ecology Research 2005, 20(5):519-527.

5. Piñeiro G, Paruelo JM, Oesterheld M: Potential long-term impacts of livestock introduction on carbon and nitrogen cycling in grasslands of southern South America. Global Change Biology 2006, 12(7):1267-1284.

6. Conant RT, Paustian K, Elliott E: Grassland management and conversion into grassland: effects on soil carbon. Ecological Applications 2001, 11(2):343-355.

7. Wang J, Sha $L Q, L i J Z$, Feng $Z L: C_{2}$ efflux in subalpine meadows under different grazing management in Shangrila, Yunnan. Acta Ecologica Sinica 2008, 28(8):3574-3583.

8. Gao YH, Schumann M, Chen H, Wu N, Luo P: Impacts of grazing intensity on soil carbon and nitrogen in an alpine meadow on the eastern Tibetan Plateau. Journal of Food, Agriculture \& Environment 2009, 7(2):749-754.

9. Schuman GE, Reeder JD, Manley JT, Hart RH, Manley WA: Impact of grazing management on the carbon and nitrogen balance of a mixed-grass rangeland. Ecological Applications 1999, 9(1):65-71.

10. Wienhold BJ, Hendrickson JR, Karn JF: Pasture management influences on soil properties in Northern Great Plains. Journal of Soil and Water Conservation 2001, 56(1):27-31.
11. Wang YF, Chen ZZ, Tieszen LT: Distribution of soil organic carbon in the major grasslands of Xilingole, Inner Mongolia, China. Acta Phytoecologica Sinica 1998, 22(6):545-551.

12. Derner JD, Beriske DD, Boutton TW: Does grazing mediate soil carbon and nitrogen accumulation beneath $C_{4}$, perennial grasses along an environmental gradient? Plant and Soil 1997, 191(2):147-156.

13. Han GD, Hao XY, Zhao MG, Wang MJ, Ellert BH, Willms W, Wang MJ: Effect of grazing intensity on carbon and nitrogen in soil and vegetation in meadow steppe in Inner Mongolia. Agriculture, Ecosystems and Environment 2008, 125(1-4):21-32.

14. Ingram LI, Stahl PD, Schuman GE, Buyer JS, Vance GF, Ganjegunte GK, Welker JM, Derner JD: Grazing impacts on soil carbon and microbial communities in a mixed-grass ecosystem. Soil Science Society of America Journal 2008, 72(4):939-948.

15. Mirsky $S B$, Lanyon $L E$, Needelman BA: Evaluating soil management using particulate and chemically labile soil organic matter fractions. Soil Science Society of American Journal 2008, 72(2):180-185.

16. Weil RR, Islam KR, Stine MA, Gruver JB, Samson-Liebig SE: Estimating labile carbon for soil quality assessment: a simplified method for laboratory and field use. American Journal of Alternative Agriculture 2003, 18(1):3-17.

17. Zhang SJ, Xiang WH, Xu GL: Distribution of soil labile organic carbon and carbon pool management Index in different regeneration Pattern of Cunning hamia lanceolata Forest lands. Journal of Soil and Water Conservation 2009, 23(4):213-226.

18. Ma XZ, Wang YF, Wang JZ, Li CS: Impacts of grazing on soil fractions in the jgrasslands of Xilin river basin, Inner Mongolia. Acta Phytoecologica Sinica 2005, 29(4):569-576.

19. Geng YQ, Yu XX, Yue YJ, Li JH, Zhang GZ: Active organic carbon pool of coniferous and broad-leaved forest soils in the mountainous areas of Beijing. Forestry studies in China 2009, 11(4):1-6.

20. Shen H, Cao ZH, Hu ZY: Characteristics and Ecological effects of the active organic carbon in soil. Chinese Journal of Ecology 1999, 18(3):32-38

21. Yang LX, Pan JJ: Progress in the study of measurements of soil labile organic carbon pool. Chinese Journal of Soil Science 2004, 35(4):502-506.

22. Burt $\mathrm{R}$ : Soil survey laboratory methods manual, Soil survey investigations report No.42 version 4.0. Lincoln, NE: Natural Resources Conservation Service, U.S. Department of Agriculture; 2004.

23. Gregorich $E G$, Ellet $B H$ : Light fraction and macroorganic matter in mineral soils. In Soil sampling and methods of analysis. CRC Press, Boca Raton, Florida, USA:Cater, M R 1993:397-407.

24. Neff JC, Townsend AR, Gleixner G, Lvehman SJ, Bowman WD: Variable effects of nitrogen additions on the stability and turnover of soil carbon. Nature 2002, 419(6910):915-917.

25. Blair JG, Lefroy RDB, Lisle L: Soil carbon fractions based on their degree of oxidation, and the development of a carbon management index for agriculture systems. Australian Journal of Agriculture Research 1995, 46(7):1459-1466.

26. Zhang HB, Tang HJ, Yang GX, Li G, Chen BR, Xin XP: Change of spatialtemporal characteristics based on MODIS NDVI data in Inner Mongolia grassland from 2000-2008. Transactions of the CSAE 2009, 25(9):168-175.

27. Yin JH, Lu XS: Construction of evaluation indicator systems of China grassland ecological function. Acta Ecologiaca Sinica 2009, 29(5):2622-2630.

28. Zhang FR: Soil Geography. China Agriculture Press, Beijing, China; 2001, 156-161.

29. Wang MJ, Ma CS: A study on methods estimating carrying capacity of grassland. Grassland of China; 1994, , 5: 19-22.

30. Wei ZJ, Han GD, Yang J, Lü X: The response of Stipa brevif lora community to stoNGing rate. Grassland of China; 2000, , 6: 1-5.

31. Scientific committees of China ecosystem research network: Protocols for standard soil observation and measurement in terrestrial ecosystems. China Environmental Science Press, Beijing, China; 2007.

32. Liu GS: Soil physical and chemical analysis \&description of soil profiles. Standards Press of China, Beijing, China; 1996.

33. Lefroy RDB, Blair GJ, Strong WM: Changes in soil organic matter with cropping as measured by organic carbon fractions and $13 \mathrm{C}$ natural isotope abundance. Plant and Soil 1993, 155/156(1):399-402.

34. Liski J: Variation in soil organic carbon and thickness of soil horizons within a boreal forest stand - effect of trees and implications for sampling. Silva Fennica 1995, 29(4):255-266. 
35. Li Z, Sun B, Lin XX: Density of soil organic carbon and the factors controlling its turnover in east China. Scientia Geographica Sinica 2001, 21(4):301-307.

36. Barget NN, Ojima DS, Belnap J, Wang SP, Wang YF, Chen ZZ: Changes in plant functional groups, litter quality, and soil carbon and nitrogen mineralization with sheep grazing in an Inner Mongolian grassland. Journal of Range management 2004, 57(6):613-619.

37. Miegroet HV, Boettinger JL, Baker MA, Nielsen J, Evans D, Stum A: Soil carbon distribution and quality in a montane rangeland-forest mosaic in northern Utah. Forest Ecology and Management 2005, 220(1-3):284-299.

38. Fan HW, Jia XH, Zhan gJG, Ma FY, Li XR: Influence of soil degradation and desertification on soil carbon cycling in arid zones. Journal of Desert Research 2002, 22(6):525-533.

39. Pan GX: Study on carbon reservoir in soils of China. Bulletin of Science and Technology 1999, 15(5):330-332

40. Stavi I, Ungar ED, Lavee H, Sarah P: Grazing-induced spatial variability of soil bulk density and content of moisture, organic carbon and calcium carbonate in a semi-arid rangeland. Catena 2008, 75(3):288-296.

41. Reeder JD, Schuman GE, Morgan JA, Lechain DR: Response of organic and inorganic carbon and nitrogen to long-term grazing of the short-grass steppe. Environment Management 2004, 33(4):485-495.

42. Yang LF, Li GT, Zhao XR, Lin QM: Profile distribution of soil organic and inorganic carbon in chestnut soils of Inner Mongolia. Ecology and Environment 2007, 16(1):158-162.

43. Holt JA: Grazing pressure and soil carbon, microbial biomass and enzyme activties in semi-arid northeastern Australia. Applied Soil Ecology 1997, 5(2):143-149

44. Franzluebbers AJ, Arshead MA: Particulate organic carbon content and potential mineralization as affected by tillage and texture. Soil Science Society of American Journal 1997, 61(5):1382-1386.

45. Elzein A, Balesdent J: Mechanistic simulation of vertical distribution of carbon concentrations and residence times in soils. Soil Science Society of America Journal 1995, 59(5):1328-1335.

46. Hong H, Hang GD, Zhao ML, Suo PF, Pan LR: Grazing intensity effects on soil property of range sites in Hunshandake sand land. Pratacultural Science 2004, 21(12):108-111.

47. Zhang $\mathrm{YW}$, Han JG, Li ZQ: A study of the effects of different grazing intensities on soil physical properties. Acta Agrestia Sinica 2002, 10(1):74-78.

48. Dormaar JF, Smoliak S, Willms WD: Vegetation and soil responses to short-duration grazing on fescue grasslands. Journal of range Management 1989, 42(3):252-255.

49. Su YZ, Zhao HL: Influences of grazing and exclosure on carbon sequestration in degraded sandy grassland, Inner Mongolia, North China. Environmental Science 2003, 24(4):23-28,

50. Zheng SH, Zhao ML, Han GD, Hong H, Gui MQ, Wu L: Relationship between soil physical properties and vegetations in typical steppe under different grazing gradients. Journal of Arid Land Resources and Environment 2005, 19(7):199-203.

doi:10.1186/2193-1801-2-S1-S1

Cite this article as: Cao et al.: Effects of grazing intensity on soil labile organic carbon fractions in a desert steppe area in Inner Mongolia. SpringerPlus 2013 2(Suppl 1):S1.

\section{Submit your manuscript to a SpringerOpen ${ }^{\mathcal{O}}$ journal and benefit from:}

- Convenient online submission

- Rigorous peer review

- Immediate publication on acceptance

- Open access: articles freely available online

- High visibility within the field

- Retaining the copyright to your article

Submit your next manuscript at $\gg$ springeropen.com 